\title{
La "novela épica". Nacionalismo carismático y vanguardia en América Latina ${ }^{1}$
}

Ricardo Roque Baldovinos

UCA, San Salvador

RESUMEN: Este ensayo analiza la novela latinoamericana del siglo $X X$ a partir de las relaciones entre las comientes políticas $y$ estéticas contemporáneas. El autor plantea que la producción novelística más innovadora es producto de la buisqueda de una expresión adecuada para la experiencia latinoamericana de la modernidad.

ABSTRACT: This essay analyses the Latin American novel of $20^{\text {th }}$ century taking into account the relations between the contemporary political and esthetical trends. The author poses that the most innovating novelistic production is the result of the search of an adequate expression for the Latin American experience of modemity.

La modernidad en América Latina no nos conduce a la jaula de hierro weberiana. ¿Qué sentido podemos entonces atribuirle a nuestra experiencia moderna? Un paso necesario para su teorización es comprender la concreción de la temporalidad latinoamericana. Y pensar el tiempo en tales términos requiere de una explicación de las maneras en que la temporalidad se configura narrativamente, puesto que es a través del acto de 
narrar que el tiempo se vuelve tangible. Ello nos lleva a una investigación sobre la novela, la forma narrativa más compleja y ambiciosa. No es fortuito que la forma de la novela tuviese que ser reinventada en América Latina durante el siglo $\mathrm{XX}$, lo que dio como resultado un recurso literario original y emulado por tadas partes. No podía ser de otra manera. La novela conlleva una experiencia de tiempo, la cual origina esta paradójica cualidad de repetición y diferencia.

Este ensayo intenta comprender la novela latinoamericana del siglo $\mathrm{XX}$ tomando en cuenta las intrincadas relaciones entre las corrientes políticas y estéticas contemporáneas. La producción novelística más innovadora resulta de la búsqueda de la forma adecuada para la experiencia latinoamericana de la modernidad. Ello arroja innovaciones en la configuración del espacio-tiempo, o cronotopo, y en la perspectiva narrativa. Este nuevo cronotopo visibiliza la simultaneidad de un espacio-tiempo heterogéneo, una característica notoria de las formaciones sociales latinoamericanas; en tanto que, la perspectiva narrativa inaugura un nuevo modelo de autoridad literaria. En lugar del autor implícito legitimado por el saber racional, característico de la novela burguesa del siglo XIX, encontramos aquí una autoridad "épica" que produce una nueva intersubjetividad de carácter carismático. Pretendo demostrar más abajo que la originalidad de esta forma literaria consiste en su capacidad de contener una crítica de la racionalización, que presenta una visión que continúa y supera la crítica de la modernidad que usualmente se atribuye a los movimientos de vanguardia artística.

De entrada, se vuelve necesario advertir que no pretendo abarcar la totalidad de la novelística latinoamericana del siglo veinte. Se notará que dejo de lado la novelística urbana. Este tipo de novela prolifera en el Cono Sur, principalmente, y aborda la experiencia de anonimato y alienación de manera muy similar a como lo hace la novela metropolitana de los mismos años. Por el contrario, la novelística que me interesa enfocar dirige sus esfuerzos a la recreación de un espacio social más amplio que registra e integra un espectro heterogéneo de temporalidades. Tradicionalmente, este tipo de novela se reúne bajo la etiqueta de "realismo mági-

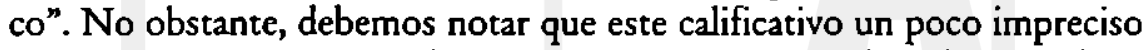
se ha vuelto una etiqueta desorientadora acuñada por la industria editorial. En este sentido, la categoría de realismo mágico se ha diluido en un nuevo lugar común de la industria de la cultura, para designar una mercancía cultural que alimenta el insaciable apetito de autenticidad del lector desencantado de la metrópolis. 
Esta degradación de hecho traiciona las ricas connotaciones que Carpentier pretendió dotar la expresión "lo real maravilloso", al inventarla en su prólogo a $E l$ reino de este mundo, novela publicada en 1949. Lo "real maravilloso" ejemplifica el esfuerzo de reconciliar la estética de vanguardia, particularmente el surrealismo, con una función más tradicional de la forma novelística, la de representar la sociedad como una totalidad compleja. No obstante el hecho de que el término "real maravilloso" es históricamente más preciso del que propongo, prefiero usar un nuevo oxímoron para esta forma de novela, "la novela épica"2. Pretendo demostrar que uno de los objetivos de esta nueva forma es romper la tregua que la forma novela había establecido previamente con la experiencia moderna. Esto lo podemos encontrar expuesto magistralmente por Georg Lukács en su Teoría de la novela ${ }^{3}$.

Con este propósito en mente, me daré a la tarea de estudiar la "novela épica" latinoamericana en la confluencia de la reformulación del nacionalismo latinoamericano durante la primera mitad del siglo XX y la recepción de la estética de vanguardia, particularmente el ideario del surrealismo. Esta coincidencia de preocupaciones artísticas y políticas se volverá más clara si somos concientes del hecho de que la renovación de las formas literarias no es un asunto exclusivamente estético. Esta renovación tiene lugar en un momento en que el agotamiento del imaginario liberal es más que visible, y dado que este imaginario ha dado forma a los proyectos nacionales latinoamericanos, se vuelve una tarea urgente que las búsquedas artístico-formales den cuerpo a nuevos horizontes de sentido. En este sentido, también se comprende que muchas autores viesen afinidades entre la crítica vanguardista de la modemidad y sus propias aspiraciones de renovación nacional.

En este sentido, resultan reveladoras las carreras de aquellos autores que comenzaron sus carreras literarias en la década de 1920. Especialmente debemos considerar a dos novelistas que fueron protagonistas en esta renovación de la forma de la novela: Miguel Ángel Asturias (18991975) y Alejo Carpentier (1904-1980). Ambos fueron testigos o participantes activos de la vanguardia parisiense y del nacimiento y expansión de la revolución cultural surrealista. Sin embargo, su inmersión en la corriente vanguardista no fue únicamente una respuesta al imperativo de ser moderno. Una nueva forma de nacionalismo animó también a esta generación, y fue precisamente este impulso lo que hizo posible la coincidencia de los intereses artísticos y políticos. A través de la literatura y el periodismo cultural, esta generación sentó las bases de la "novela épica" y 
de una nueva estética latinoamericana. Por lo tanto, lo que estos autores lograron no fue simplemente la importación de una nueva tendencia o una sustitución de un paradigma, sino un verdadero canibalismo cultural, como lo imaginó el brasileño Oswald de Andrade en su célebre Manifiesto antropofágico. Es importante, sin embargo, subrayar que el objetivo de este canibalismo fue la revolución de la sociedad por los medios del arte, y que el espacio virtual de la novela se esperaba que era el lugar de este experimento.

\section{Nacionalismo carismático}

Para comprender la clase de nacionalismo que influyó las sensibilidades del primer tercio del siglo XX, es preciso tener en mente la crisis del modelo liberal de organización nacional, tanto en sus formas externas como en sus referentes imaginarios. Esta crisis fue el resultado de factores ideológicos y materiales, incluyendo el estatus neocolonial de las sociedades latinoamericanas en el escenario internacional, la sospecha del aumento del poder imperial de los Estados Unidos, la perversión de la democracia liberal mediante nuevas formas de autoritarismo y la profundización de las desigualdades sociales y regionales. António Cândido indica que esta situación condujo a una alteración importante en la conciencia de América Latina, el cual fue de una conciencia de "país nuevo" a una de "país atrasado" . De esta forma, el carácter problemático de la condición moderna, derivada de la contradicción entre ideales y realidades, se hizo patente entre la intelectualidad. El nuevo siglo comienza con un sentido de bancarrota de los ideales liberales e ilustrados: el individualismo, la economía de mercado, la secularización, y la fe en el poder emancipador de la ciencia y la tecnología, para hacer mención de los más importantes.

Esta nueva conciencia nacional se designa usualmente como antiimperialismo ${ }^{5}$. Seguramente se desarrolló, al menos en parte, a partir de una reacción al neocolonialismo, que al final del siglo XDX se había vuelto una realidad palpable. Un evento histórico decisivo en este contexto fue la Guerra Hispano-estadounidense de 1898, denunciada firmemente por Rubén Darío y José Enrique Rodó.

Sin embargo, es importante notar que esta nueva sensibilidad nacional no es únicamente reactiva. Propone una nueva identidad cultural que unifica todo el espectro de ex-colonias españolas del continente americano. En esta línea, la característica más importante del nuevo espíritu es la redefinición del sujeto nacional. Para la imaginación liberal, era bastante 
claro que la elección por la "civilización" requería una entidad política nacional: un estado racional constituido por individuos libres y autónomos. Los escritos de algunos de los más importantes ideólogos del liberalismo -Simón Bolivar, Andrés Bello y Domingo Faustino Sarmiento- se preocupan en fundamentar este ideal.

Sólo unas cuantas generaciones después, sin embargo, el panorama había cambiado dramáticamente. En vez del nacionalismo romántico, consonante con la imaginación liberal, irrumpe un nacionalismo carismático. En todo el espectro ideológico, ideas despreciadas y en desuso ganaron una nueva legitimidad. Casi todos parecían cómodos con nociones como: comunidad, tradición, primacía de lo instintivo y, especialmente, con una celebración de lo bárbaro como la auténtica esencia de la cultura latinoamericana. Gradualmente, la utopía racional es reemplazada por el ideal de una comunidad carismática, por el retomo de la tribu, en otras palabras, por una utopía arcaica que recupera lo primitivo.

Russell A. Berman, germanista norteamericano, ha elaborado la noción de comunidad carismática para explicar el proceso cultural de las sociedades europeas en los albores del siglo XX. ${ }^{6}$ Desarrollando sus ideas a partir del pensamiento de Max Weber, Berman explica que las creencias religiosas, en su carácter de guías de prácticas mundanas, pueden ser generadoras efectivas de transformaciones sociales. Weber toma prestado el término "carisma" del debate teológico protestante de su país. En esta tradición religiosa, el aparato jerárquico se identificaba con el catolicismo romano y contrastaba con una forma diferente de organización religiosa, una que se remontaba a los primeros cristianos y que había inspirado la reforma. El cristianismo primitivo era más espontáneo y dependiente del compromiso personal, mucho antes de la excesiva institucionalización de la Iglesia; en cuanto heredera de la burocracia del imperio romano, pervirtió ese espíritu.

En este esfuerzo por recobrar la relación entre fe y organización, Rudolf Sohm, un teólogo, usó el término "carisma" en un sentido cercano al de Max Weber. Sohm insistió en la incompatibilidad entre cualquier forma de jerarquía y legalidad racional y la esencia del cristianismo. Sostuvo el término "carisma" como el único modo apropiado de relación cristiana, ya que la iglesia apostólica original era una comunidad carismática, o sea, "un grupo social sin administración burocrática o restricción legislativa y caracterizado por una participación colectiva en un significado compartido, la nueva fe"'. Esta comunidad se caracterizaba por la ausencia 
total de legislación y el rechazo de cualquier división del trabajo, que no reflejara la auténtica vocación de los miembros individuales. La ley no tenía lugar en una comunidad carismática, ya que era el espíritu y no el formalismo legal el principio de la organización. ${ }^{8}$

Esta concepción de un colectivo alternativo, o la comunidad carismática, apareció como la posible solución a la bancarrota del ideal ilustrado de una sociedad organizada de manera racional. Se presentaba como la anticipación de una forma de sociabilidad en la cual se podía superar la crisis modema de sentido y dejar así el camino abierto a solidaridades cohesivas. Es obvio que esta noción estaba condenada a estimular el rebalse de lo religioso en los ámbitos político, ideológico y artístico, y se sigue de ello que este concepto emergería en distintas manifestaciones, ofreciendo cada una nueva mística, que habría de contrarrestar la parálisis moderna.

El embrujo de la comunidad carismática alcanzó América Latina a través del ámbito estético. ${ }^{9}$ Sus fuentes son diversas, pero la mayoría nos conducen a varios pensadores europeos críticos de la modemidad, quienes fueron diseminados por medio de las páginas de la Revista de Occidente, fundada y dirigida por José Ortega y Gasset. ${ }^{10} \mathrm{~A}$ pesar de la escasez de colaboradores latinoamericanos, el impacto de esta publicación en la vida cultural de la región fue determinante. ${ }^{11}$ Por medio de traducciones de Gaos, García Morente y el propio Ortega, los lectores españoles y latinoamericanos se mantuvieron al día con las ideas de pensadores como Oswald Spengler, Max Scheller, Georg Simmel y Sigmund Freud.

De este amasijo de ideas, pondremos atención a aquellas que enfatizaron la decadencia de la cultura europea y reclamaron la necesidad de una crítica del eurocentrismo. Un libro leído con especial atención fue $\mathrm{La}$ decadencia de Occidente, de Oswald Spengler'2. En este voluminoso estudio, Spengler homologa las civilizaciones a los organismos biológicos y sostiene que cada cual debe experimentar un ciclo similar de nacimiento, crecimiento, decadencia y muerte. Cada civilización, según Spengler, es una entidad independiente $e$ incomunicada y, por consiguiente, la sucesión de una civilización por una nueva es similar a la sustitución de un organismo viejo por uno nuevo. La muerte de una civilización implica la desaparición total de su legado, y no hay esperanza de que las nuevas puedan recobrarlo. Es importante notar que este ciclo de juventud y decrepitud parece ser completamente irracional. En contraste con otros filósofos de la historia como Giambatista Vico o Comte, para Spengler, 
la capacidad reflexiva no era un signo de madurez sino de caducidad y muerte inminente. De forma paralela, la fe y la espontaneidad, como las que se hallan en comunidades carismáticas, se veían como síntoma de vigor juvenil.

No es difícil darse cuenta de los poderes seductores de estas ideas. Los intelectuales latinoamericanos estaban ansiosos de diferenciarse de un continente europeo que consideraban intimidante a causa del esplendor de su tradición cultural. La Primera Guerra Mundial le otorgaría credibilidad a estas ideas de renovación cultural. Para muchos europeos y no europeos, la guerra sería la clara señal de decrepitud del viejo mundo y un llamado para la nueva civilización por venir. Algunos latinoamericanos le haría eco, redescubriendo los signos de una alteridad cultural rechazada hasta entonces como marca de barbarie.

De esta forma, el nacionalismo carismático se convirtió en uno de los referentes de la intelectualidad latinoamericana del siglo XX, revitalizando su misión renovadora. Esta sensibilidad antimoderna estuvo también presente en el espíritu de la vanguardia artística, donde tuvo especial influencia, dado que los intelectuales que mediaron en la recepción del pensamiento antimoderno europeo eran, en su mayoría, escritores y artistas. Por esta razón, podría ser útil revisar el diálogo con la vanguardia, de la cual algunos de ellos participaron entusiasta y activamente.

\section{Surrealismo y renovación carismática}

Es imposible comprender el significado del surrealismo en la cultura literaria latinoamericana si se le reduce a un simple movimiento artístico, a un mero "ismo" entre otros. El surrealismo, con todas sus extravagancias, representa una crítica ambiciosa de la cultura burguesa, si bien en una dirección diferente a la pensada después por los escritores latinoamericanos.

Del surrealismo viene el concepto de lo "maravilloso". El término fue acuñado primero por Breton. Luego, lo retomó Carpentier para su fórmula de lo "real maravilloso". Para Breton y los surrealistas, el mundo, como se presenta a la mirada reflexiva de la conciencia occidental, es una ilusión. Detrás de estas apariencias subyace una realidad mucho más fundamental: instintos, deseos, potencias libidinales, etc. En este punto, es importante subrayar una diferencia fundamental entre surrealismo y psicoanálisis. Ambos reconocen la instancia del deseo y lo irracional de la vida, pero, para el psicoanálisis el objetivo es extender el dominio del ego. En otras palabras, el psicoanálisis, privilegia las capacidades racionales, si bien re- 
conociendo la existencia de lo instintivo y evitando el exceso de represión. Para el surrealismo, el objetivo es destruir el sujeto racional, exponer la falsedad de la civilización. Con este objetivo, las técnicas artísticas surrealistas, tales como el collage, la libre asociación de ideas e intoxicación, proponen la destrucción tanto del lenguaje como de la forma orgánica artística. Es a través de esta destrucción que podría emerger una realidad informe, magmática, pero más auténtica y verdadera.

El surrealismo, por tanto, encarna un ataque frontal a la razón occidental. Para el surrealismo, la emancipación es sinónimo de la liberación de los instintos de cualquier voluntad conciente y la destrucción de las instancias racionales que han apresado al sujeto moderno en la jaula de hierro weberiana. En un mundo donde el significado se ha evaporado, el surrealismo predica su recuperación mediante la destrucción de la cultura, o al menos la destrucción de aquella que funciona a través del deseo reprimido.

Este giro radical e intransigente es, sin embargo, el síntoma de la condición marginal de la vanguardia ${ }^{13}$. En vista de la imposibilidad de un camino viable, desde el punto de vista político, para la transformación de las asfixiantes maquinarias sociales, la élite estética sobrevive en los espacios marginales de resistencia cultural. Este repliegue y la asimilación de la agenda contestataria surrealista dentro de la industria cultural, marcaría los límites de su aceptación por parte de los escritores latinoamericanos que se sienten de alguna forma optimistas sobre los prospectos de renovación nacional por la vía de la cultura. ${ }^{14}$

Por esta razón, no es fácil asimilar la vanguardia latinoamericana a su contraparte europea. Existe una diferencia importante en relación al lugar del artista en la sociedad. El escritor del Sur tendría la oportunidad de un protagonismo social activo que no tiene paralelo en el Norte. Esto se debe al mayor grado de diferenciación social en el último caso, en el que es posible mayor autonomía, pero únicamente al precio de un creciente aislamiento.

Ahora dirijamos la atención a las carreras de dos mediadores estratégicos de la Vanguardia en Europa y América Latina. La investigación más difundida sobre literatura vincula a Miguel Ángel Asturias y Alejo Carpentier al surrealismo. ${ }^{15}$ Ambos pasan varios años en París y siguen muy de cerca el desarrollo artístico de este movimiento. Carpentier, por ejemplo, se mantuvo muy cerca de algunos surrealistas, especialmente de 
un grupo que se volvió disidente luego de uno de los frecuentes cismas que los caracterizaron. Fue amigo de Robert Desnos, Michel Leiris y Henri Michaux. Él también publicó algunos artículos en una de las revistas del círculo, y colaboró en un espectáculo musical organizado por Edgar Varèse, así como en una película dirigida por Man Ray.

Asturias y Carpentier desarrollaron además un intenso trabajo en el periodismo cultural. Estuvieron a cargo de seguir la actividad artística francesa en nombre de los lectores de sus respectivos países. ${ }^{16}$ Esta peculiar relación se transparenta en los positivos comentarios de Asturias sobre el surrealismo:

"Para nosotros, el surrealismo representa (y esta es la primera vez que lo digo, pero creo que lo tengo que decir) el encuentro dentro de nosotros mismos, no la parte europea, sino la indígena y americana; ya que viene de la escuela freudiana y actúa sobre lo inconsciente y no sobre lo consciente. Teníamos el inconsciente muy oculto bajo una consciencia occidental. Pero cuando cada uno comenzó a inspeccionar dentro, cada uno encontró el inconsciente indígena, lo que nos otorgó la posibilidad de escribir". ${ }^{7}$

\section{Y continúa:}

"Lo que trato de decir es que la escuela surrealista, que ejerce una gran influencia en toda la literatura, es una escuela revolucionaria de grandes poetas, nos ayuda a escribir. Siguiendo la teoría de la escritura automática, hicimos experimentos de escribir sin la vigilancia de la inteligencia. El surrealismo, para los escritores latinoamericanos y especialmente para mí, fue una gran posibilidad de independencia de los modelos occidentales. El surrealismo despertó en nosotros el sentimiento. Favoreció nuestra tendencia a sentir cosas en vez de pensarlas". ${ }^{18}$

El elemento más atractivo de estas líneas es la relectura de la topografía del sujeto freudiano en clave nacionalista. Aquí, la cultura ancestral maya es el inconsciente, mientras que la instancia racional es el racionalismo occidental. Si el surrealismo privilegia lo irracional, legitimando así lo vernáculo, contribuye simultáneamente a la tarea de fortalecer la noción de comunidad carismática, mediante el énfasis en lo instintivo, o vínculos primarios sobre aquellos organizados racionalmente.

Asturias no se siente urgido a examinar críticamente su relación con el surrealismo. Carpentier, por el contrario, se siente impulsado a investigar con cierta profundidad. Sus críticas giran alrededor de dos temas. 
Primero, denuncia la banalización del surrealismo. Al no estar apto para trascender la política del escándalo, de "épater le bourgeois", el potencial iconoclasta del surrealismo se pierde. Aún más, la industria de la cultura termina domesticando su impulso más subversivo. Carpentier formula esta queja a un periódico venezolano de los años cuarenta:

"Usted ha notado que las técnicas del surrealismo, transformado en moneda corriente, son ahora comunes en anuncios, en posters, en vitrinas de tiendas de departamento. Las "fantasías" que las mujeres suelen tener en estos tiempos, obtienen ventajas infinitas de los hallazgos de las artes visuales surrealistas. El surrealismo está ahora desprovisto de todo su polémico potencial y, por esta simple razón, está muerto como movimiento artístico". ${ }^{19}$

La segunda crítica consiste en apuntar lo inadecuado de las técnicas surrealistas para evocar lo maravilloso de América Latina. Esto lleva a Carpentier a desarrollar una nueva forma de praxis artística, una en la cual lo maravilloso es comprendido no como una dimensión oculta de la realidad, sino como una fuerza efectiva en un mundo civilizado superficialmente. Lo maravilloso es invisible solamente a la conciencia desorientada de una élite, la cual obstinadamente niega su mitad bárbara. Estas son las palabras de Carpentier:

"En América Latina, el surrealismo es una parte de los hábitos de la vida diaria; es domesticado, sentido, en la simple proliferación de hongos... esta noción ciertamente me lleva a concluir que la narración de ceremonias, tradiciones y leyendas de ciertos cabildos negros en Cuba podrían ser más interesantes que la búsqueda de, como lo quería Lautreámont, "la belleza del encuentro fortuito de una sombrilla y una máquina de coser sobre una tabla de disección." Quiero subrayar que no quiero desechar el movimiento surrealista. Creo que es un asunto de positivo interés y ha tenido un rol de importancia innegable. Pero prefiero la materia viviente, el grito, la pura creación dada a nosotros por medio de nuestro mundo natural. ${ }^{20}$

Para el reconocimiento de esta dimensión de realidad, no es suficiente producir efectos de choque, como en el surrealismo. Se requiere de un esfuerzo intensivo de investigación histórica:

'Y súbitamente descubrí que estaba, en todo esto, una historicidad maravillosa que era de lo que en mi opinión carecía el surrealismo. En el surrealismo, el elemento fantástico era general- 
mente arbitrario, bello pero totalmente arbitrario u onírico. Pero yo me encontré en Sudamérica y Haití ante gente con el poder de transformarse en animales, con reyes increibles, ante personajes a lo Lautréamont, $y$ todo esto en un contexto de una era y en el contexto de la veracidad histórica."

De las dos críticas de Carpentier, la primera emerge de un punto de vista cómodo y retrospectivo. Es, por lo tanto, anacrónico e injusto en su valoración del surrealismo en su estadio "heroico". Mucho más interesante es la segunda crítica. Aquí sus intereses políticos y estéticos se juntan. En otras palabras, encontramos en ese sitio un claro intento de derivar a la política desde su estética. Esta confluencia se sustenta en el nacionalismo carismático y en el rol que se asigna a la cultura estética en la refundación de las sociedades latinoamericanas.

En una serie de crónicas de viaje de Carpentier y en el interior venezolano, encontramos un pasaje que es bastante revelador de la importancia del ideal de comunidad carismática. Esto expresa una estetización de lo primitivo: Esto es, de lo maravilloso como una fuerza efectiva en la realidad latinoamericana. ${ }^{22}$ Una crónica narra el encuentro del autor con un aventurero español que se ha establecido en un remoto rincón de la selva venezolana:

"Tal vez lo que él buscaba en esa grandiosa soledad de la Gran Sabana, este pequeño farmacéutico valenciano, era, precisamente, un país sin gobierno, a fin de imponerse reglas él mismo, sabia y correctamente. Este aventurero que llegó caminando en busca de la leyenda de El Dorado dejó tras de sí, hace más de veinte años, una realidad despreciable de mazmorras, olores fétidos y adulaciones, a fin de fundar, en esta Santa Elena de Vairén, bajo un techo de hojas, al lado de la mujer del Génesis, una utopía que encaja en su misteriosa evocación, en sus sueños más profundos. 'Únicamente aquellos que no se lucren del oro obtenido estarán aptos para hallar el secreto de la transmutación de los metales', dice una de las leyes fundamentales de la alquimia, una ley que probablemente esconde el verdadero gran secreto de El Dorado". ${ }^{23}$

Hasta este punto, hemos visto cómo la diseminación de la idea de comunidad carismática conforma la sensibilidad de muchos intelectuales latinoamericanos. Es la concreta encarnación del antiliberalismo de la primera mitad del siglo XX. Sostengo que este proceso fue de extraordina- 
ria importancia en este peculiar diálogo con el surrealismo. Sin embargo, la originalidad de autores como Carpentier o Asturias no consiste únicamente en explicitar las peculiares dinámicas de tiempo y espacio que se muestran necesarias para la efectiva expresión del ideal carismático. Ellos también desarrollan un artefacto literario capaz de producir esta visión en sus lectores. A fin de explicar el surgimiento de este efecto, que conlleva la reinvención de la forma-novela, es necesario seguir dos pasos. Primero, hay que dar cuenta de la importancia estratégica de la forma-novela y su renovación entre los escritores latinoamericanos. Uno vez logrado esto, se podrá explicar con mayor detalle la novela "épica" y sus implicaciones. En segundo lugar, describiré la evolución de esta forma, examinando algunos casos relevantes de las novelas "épicas".

\section{La forma-novela}

Para comprender lo central de la forma de la novela en el surgimiento de una nueva autoconciencia latinoamericana, tenemos que tener en mente que las novelas no son ni criaturas caprichosas de la fantasía humana ni reproducciones inertes de la vida social. El texto de la novela es una configuración construida a partir de lenguajes y símbolos sociales, que ofrece a sus lectores un nuevo horizonte de lo real, al cual se llega mediante la experiencia estética. ${ }^{24}$ Mediante esta experiencia narrativa, la novela se presenta a los lectores con un modelo de percepción, a través de su argumento, propone un modelo de acción. También presenta una codificación del espacio, organizándolo y dotándolo de significados. Sin embargo, la novela es principalmente una organización temporal. Dota al tiempo de significado al conectar la experiencia individual, las vidas de los personajes, con la historia de un colectivo.

La mayor parte de la discusión sobre este género gira alrededor de la novela burguesa del siglo XIX, cuya expresión más notable es el realismo. Evidentemente, la novela realista no es ni un artefacto transparente ni simplemente un juego de convenciones orientadas a producir un efecto de realidad. En cuanto que cualquier artefacto cultural es un sistema de comunicación, un dispositivo que permite a sus lectores interpretar su mundo vital a través de cierta luz. El juego del lenguaje del realismo es mucho más sutil que lo que sus defensores y detractores generalmente reconocen. ${ }^{25}$ Russell A. Berman propone comprender el realismo como un sistema literario cuyo objetivo es producir un tipo específico de lector. El lector implícito del realismo sería alguien capaz de leer el mundo cual si se tratase de una novela realista. Como explica Berman, "la fun- 
ción social de la producción literaria realista es, por tanto, la producción del lector como realista, como un agente de percepción y juicio específicamente formado, integrado no únicamente dentro de la vida literaria sino también dentro de una visión particular de la sociedad burguesa de mitad del siglo XIX."26 Esta es la pragmática del realismo. Tenemos que tener esto en mente a fin de comprender la evolución que experimentó el género en el siglo XX.

Dentro de la compleja arquitectura de esta forma literaria, quisiera poner especial atención a dos elementos que caracterizarán la ".novela épica": La codificación de tiempo y espacio y la perspectiva narrativa. Para explicar el primer aspecto, usaré el concepto de cronotopo propuesto por Mikhail Bakhtin. A su vez, no consideraré la perspectiva narrativa simplemente como un asunto formal, sino como un indicador del tipo de autoridad literaria instituido dentro de una configuración textual específica.

Para Bakhtin, los géneros literarios son modos de pensar el mundo.27 La novela, por ejemplo, se relaciona íntimamente con las instituciones de tiempo y espacio y sus relaciones con la praxis humana. Bakhtin definió esta codificación de tiempo y espacio como el cronotopo, una expresión que tomó prestada de la física de Einstein. En contraste con la filosofía kantiana, para la cual tiempo y espacio son una experiencia a priori, para Bakhtin son prefiguraciones de situaciones históricas y sociales de los sujetos. El cronotopo sería entonces la forma de codificar estos aspectos de experiencia en un género narrativo.

Bakhtin intenta examinar los distintos cronotopos en la historia de la novela, desde su prehistoria helenística. Desafortunadamente, su proyecto quedó trunco. Su famoso ensayo sobre el tópico apenas llegó a explicar la temprana modernidad. Además, su análisis tendió a privilegiar el tiempo como el dinamizador más evidente del argumento, pasando por alto el espacio, que permanece en su análisis más bien como el telón de fondo de los eventos narrados. Se vuelve así necesario definir el cronotopo de la novela burguesa: el punto de contraste de la mayoría de los experimentos del siglo XX. La efectividad del realismo del siglo XIX se basa en hacer del espacio-tiempo de la novela coextensivo a las coordenadas experienciales de su lector. Sin embargo, la prefiguración de la novela realista es la experiencia del tiempo y espacio abstractos e intercambiables de la sociedad capitalista. Este mundo cuantificable se vuelve significativo cuando el héroe adquiere una personalidad coherente, al ser capaz de descifrar el mundo por medio de sus facultades racionales. El mundo 
entonces se vuelve familiar: Una codificación de lugares organiza el espacio en términos de lo público y lo privado. Además, la lógica de lo privado se extiende a los lugares públicos, de tal forma que ellos también podrían volverse familiares. El tiempo aparece como esencialmente abierto e indeterminado porque es el horizonte abierto para el progreso social $e$ individual.

¿Cómo es posible este cronotopo? Aquí es donde la perspectiva narrativa se vuelve estratégica. La perspectiva narrativa no consiste simplemente en un narrador. Comprende otros recursos, tales como focalización y comentario editorial, el establecimiento de la autoridad dentro del texto. Esto está cerca de lo que algunos críticos refieren como el "autor implícito". La novela burguesa construye una instancia especial de autoridad que presta apoyo a la búsqueda del héroe de apropiarse de un mundo extraño y abstracto. Esta autoridad depende fuertemente del establecimiento de un intercambio racional de información entre el mundo representado y el lector. Las garantías de la racionalidad de este intercambio son los discursos científicos (o pseudocientíficos) del momento. La autoridad del texto legitima constantemente el prestigio de estos discursos y viceversa.

Por medio de estos, la novela no solamente recrea el mundo sino que produce su respectivo lector, un lector congruente con la ideología hegemónica del capitalismo liberal. Por lo tanto, dentro de la institución literaria moderna, la novela realista es uno de los aspectos que produce la racionalidad liberal burguesa. Así es como una relación de lectura, en este caso construida como una comunidad de intercambio racional, constituye el fundamento para una comunidad política ideal; de aquí el atractivo de la novela, más allá del ámbito literario.

\section{Una forma fuera de lugar}

Movámonos ahora hacia América Latina, donde la ausencia de una novela realista del siglo XIX, al estilo europeo, salta a la vista. Todavía es poco frecuente toparse con una novela realista, aún entrado el siglo siguiente, a pesar de los intentos de adoptar el naturalismo, como en la novela costumbrista o vernácula y también a pesar de ciertos debates sobre el realismo social.

Si uno examina cuidadosamente títulos que la historiografía literaria denomina como realistas, tales como Cecilia Valdés, Don Segundo Sombra, La vorágine, Doña Bárbara, uno puede esperar naturalmente detec- 
tar ciertos rasgos comúnmente asociados a la tradición realista: abundancia de la descripción, intervenciones didácticas del narrador, determinismo social en la evolución de la trama, etc. Sin embargo, la esencia de la acción tiende generalmente hacia lo alegórico o truculento. De hecho, estas obras podrían equivocadamente ser tomadas como romances en vez de novelas. Al leerlas nos encontramos pues en algún punto intermedio entre lo realista, lo fantástico y lo didáctico. Que sean tan deficientes en realismo o verosimilitud puede sólo, de manera parcial, atribuirse a la relativa ignorancia del escritor sobre su ambiente social. Por el contrario, como lo ha mostrado Roberto Schwarz, la causa de este defecto estriba en lo radicalmente inadecuado de la novela burguesa con respecto a la experiencia social de América Latina. En otras palabras, como se ha mostrado antes, la novela burguesa es creible únicamente cuando la imagen del mundo que produce en sus lectores corresponde a las apariencias ideológicas de un mundo moderno racionalizado ${ }^{28}$. La modernidad y su racionalización del mundo produce un sentido común ideológico ampliamente compartido que prefigura el mundo narrativo de la novela burguesa. Ahora bien, ¿qué sentido común puede asimilar un espacio social que es intrínsecamente fragmentado y heterogéneo, donde muchos de los supuestos de la modernidad tiene, en el mejor de los casos, un estatuto incierto?

Las primeras novelas latinoamericanas buscan dar cuenta de esta realidad asumiendo un carácter hiperbólico. El recurso a la alegoría y al arquetipo es un medio desesperado de reprimir los datos más incómodos de la realidad. Por ejemplo, en Doña Bárbara, la lucha de los principios abstractos de civilización y barbarie tematiza la resistencia de la realidad a la mirada racionalizadora de Santos Luzardo. La barbarie, condensada en la figura de la protagonista femenina, es la marca de lo que la mirada del intelectual modernizante no puede asimilar. ${ }^{29}$

\section{La "novela épica"}

Existe, por lo tanto, un impasse en la adaptación de la novela a una configuración de su forma literaria, capaz de darle sentido a las peculiares dinámicas de la modernidad latinoamericana. Este impasse no cedió sino hasta el final de la década de los cuarenta. ${ }^{30}$ No sólo la sustitución de los paradigmas estéticos, sino además el desencanto con la imaginación liberal y su forma estética, la novela burguesa tuvo que ver en la reinvención de la forma novelística en América Latina en la mitad del siglo XX. La sustitución de los referentes estéticos coincidió con la búsqueda de una 
renovación carismática de las sociedades latinoamericanas. Muchos escritores vieron esta renovación como la realización de su destino histórico. Siguiendo las ideas de Spengler, Keysserling, Vasconcelos, y otros, una juvenil Latinoamérica vio este destino como el reemplazo de una Europa decadente. ${ }^{31}$

Veamos como esta renovación tiene lugar en la novela, y comencemos prestando atención al cronotopo. El espacio-riempo de la "novela épica" intenta resolver el tema de la abstracción en una dirección distinta a la que adopta la novela burguesa. En ese intento, la "novela épica" busca corregir el diseño de un mundo que condena a una particular región a la marginalidad y al atraso. El cronotopo de la "novela épica" disuelve el telos de progreso que constituye la medida universal de tiempo, instituida por un sisterna de mundo hegemonizado por el Occidente. Al hacer esto recrea esta geografía imaginaria del mundo.

El asentamiento del espacio de la "novela épica" consiste en la disolución de la dicotomía del centro y la periferia. Cada espacio aparece en su propia singularidad. Sin embargo, esta singularidad se relaciona muy de cerca con un tiempo específico. La cultura latinoamericana ya tiene sus propias codificaciones, y la primera es la designada por Sarmiento. Su dicotomía de civilización y barbarie es de hecho un cronotopo. Es una jerarquía de espacio que depende de su integración dentro de un telos universal de progreso. Esta jerarquía sólo puede desaparecer cuando los nuevos países derroten la barbarie y entren al centro al mismo tiempo. El arielismo de los albores del siglo XX, profundamente influenciado por el panlatinismo francés, añade alguna complejidad a esta configuración de espacio-tiempo. ${ }^{32} \mathrm{El}$ tiempo moderno ha dejado de ser uniforme. Existe una distinción entre la auténtica modernidad de la cultura estética europea (aquella de origen latino) y la modernidad perversa del capitalismo americano. Aún en esta concepción anterior hay implícito un telos de progreso, si bien uno particular a esos países que permanecen fieles al "espíritu latino".

Sin embargo, el impacto del surrealismo y la Vanguardia replanteará la lógica de tiempo y espacio en diferentes términos. El surrealismo y el pensamiento antimoderno denuncia la civilización occidental como falsa y decrépita. Esto demanda el surgimiento de una nueva lógica de tiempo y espacio. En este contexto es muy importante notar el descubrimiento de lo primitivo en el arte y la etnografía y atender a su lógica peculiar de tiempo y espacio. La experimentación de vanguardia coincide con el des- 
cubrimiento de lo primitivo y su valoración como una visión de mundo diferente, si no más auténtica. ${ }^{33} \mathrm{El}$ conocimiento proporcionado por la etnografia, antropología y los estudios religiosos pone a la disposición de escritores $y$ artistas la lógica que se esconde tras la mente bárbara. No es casualidad el profundo impacto que tuvo el estudio de la civilización y religión mayas en la carrera novelística de Miguel Ángel Asturias. Al asimilar la lógica interna de la mentalidad maya, él pudo remodelar la forma de la novela y hacerla más adecuada para transmitir sus experiencias de la tensión entre el mundo tradicional y el modemo. Algo similar ocurrió con Carpentier y la religión afroantillana.

Para la "novela épica", asimilar la lógica del tiempo y espacio de América Latina implica tanto el rechazo del punto de vista de un sistema jerárquico centralizado y la disolución de un tiempo abstracto y lineal. Existe una falsa geografía y una falsa temporalidad por derrotar. La solución es la construcción de un cronotopo que demuestre la cualidad heterogénea y multilateral del espacio-tiempo latinoamericano. Nadie ha sintetizado mejor el cronotopo de la "novela épica" que Anibal Quijano, un filósofo peruano. Estas son sus palabras:

“... [L]a relación entre historia y tiempo es aquí por completo diferente a como aparece en Europa o Estados Unidos. En América Latina, lo que en esas otras historias es secuencias, es una simultaneidad. No deja de ser también una secuencia. Pero es, en primer término, una simultaneidad. De ese modo, por ejemplo, lo que en Europa fueron las etapas de la historia del capital, aquí forma los pisos del capital... El tiempo en esta historia es simultaneidad y secuencia, al mismo tiempo."

Vale la pena continuar la cita:

"Se trata de una historia diferente del tiempo. Y de un tiempo diferente de la historia. Eso es lo que una percepción lineal y, peor, unilineal del tiempo, unidireccional de la historia, como la que caracteriza la versión dominante del racionalismo euronorteamericano, bajo la hegemonía de la razón instrumental, no logra incorporar a sus propios modos de producir o de otorgar sentido 'racional', dentro de su matriz cognitiva, de su propia perspectiva. $Y$ que nosotros, aunque todo el tiempo angustiados por la sospecha de su presencia, no hemos sido tampoco capaces de identificar y de asumir, plenamente, como sentido histórico 
propio, como identidad, como matriz cognitiva, porque no logramos liberarnos antes del dominio de ese racionalismo". ${ }^{34}$

Aquí no tenemos un espacio que sea absorbido por el tiempo, como en el telos de progreso o el mito de un tiempo universal. Muy por el contrario, tenemos un tiempo que es espacializado y que preserva así su especificidad.

La "novela épica" modifica también la perspectiva narrativa. El hecho que la mayoría de estas novelas usen un narrador omnisciente no debe decepcionamos. Desde un enfoque estrictamente formalista, ello pondría a la "novela épica" más cerca de la tradición realista que los experimentos modernistas contemporáneos, caracterizados por un subjetivismo extremo. Sin embargo, la función del narrador omnisciente en la "novela épica" es también completamente diferente de su contraparte en el realismo. Como se advirtió más arriba, el realismo instituye una autoridad racional que requiere el desapego de una perspectiva narrativa impersonal. La omnisciencia de la "novela épica" es, por el contrario, la expresión de una autoridad carismática. No recurre a un conocimiento racional o científico sino a algo bien diferente. La mayoría de "novelas épicas" hablan con una voz que, lejos de ser abstracta, es la encarnación del colectivo carismático. En esta forma, la perspectiva narrativa intenta suturar la heterogeneidad contenida en el cronotopo.

\section{El camino de la "novela épica"}

Hasta este punto, es importante observar de cerca los trabajos de la "novela épica", examinando algunos textos concretos. El primero es $E l$ reino de este mundo (1948), de Alejo Carpentier, en cuyo prólogo su autor acuñó la famosa noción de "lo real maravilloso". Como se ha dicho antes, la crítica de Carpentier del surrealismo y su propuesta de superarlo descansa en lo que González Echeverría denomina la ontologización de lo maravilloso. ${ }^{35}$ Aquí la forma de la "novela épica" es sólo parcialmente desarrollada. Su cronotopo claramente espacializa el tiempo, pero su perspectiva narrativa permanece cercana a la novela burguesa. Esto es probablemente así porque $E l$ reino de este mundo es una parodia de una novela histórica, en la cual esta forma se deconstruye pero aún se rehusa a convertirse en una nueva forma. El primer capítulo establece una tensión entre el mundo de los colonizadores franceses y el del joven esclavo. Imbricado dentro de la imaginería del iluminismo representado por las frías y abstractas impresiones del rey y su hijo, tenemos los vívidos mitos 
de esclavos más viejos. Un conflicto de espacios y tiempos culmina en la incorporación de la temporalidad del mito y su inescapable lógica de repetición: la eterna oscilación de la opresión y la emancipación. Sin embargo, una distancia narrativa que se sustenta en la evidencia histónica para autorizar su narración, guía el texto. La lógica de la novela cuestiona claramente la noción de tiempo histórico y reconoce el poder del mito como una fuente de esperanza y cambio social. Sin embargo, enfrenta un dilema entre las dos lógicas de tiempo, que es incapaz de resolverlos en términos narrativos. De allí deriva el célebre y comentado último capítulo, donde el narrador debe ejercer la función editorial a fin de demostrar la importancia del mito, distanciándose al mismo tiempo de las connotaciones pesimistas de su lógica de la repetición.

La segunda novela que merece comentario es Hombres de maiz (1949) de Miguel Ángel Asturias. Es un trabajo más complejo, ambicioso y hermético, además es una "novela épica" también en otro sentido, pues le llevó a Asturias más de veinte años concluirla. Escribió varios pasajes densamente líricos, en la década de 1920, pero fue hasta la 1940 que logró concebir una estructura para integrar ese heterogéneo material. El estudio que Asturias realizó de la religión y civilización mayas, en el París de la década de 1920, bajo la dirección de Georges Raynaud y Joseph-Louis Capitan, influenció profundamente la arquitectura y el estilo de la novela. ${ }^{36}$ Al mismo tiempo, la atmósfera y estilo de muchos pasajes revela claramente la influencia del surrealismo. El espacio-tiempo debe mucho a la lógica del mito, donde el espacio borra el tiempo lineal. La irrupción del mundo de los ancestros en lugares sagrados rompe el flujo del tiempo histórico e instaura el tiempo cíclico de la comunidad carismática. Sin embargo, es la perspectiva narrativa lo que forma el aspecto más innovador de esta novela, al compararla con la de Carpentier. En Hombres de maíz, el narrador omnisciente es una síntesis de todos los registros posibles. Encontramos lo mágico y lo "científico". El último, por ejemplo, es el que organiza el pasaje donde el sacerdote de San Miguel de Acatán intenta sin éxito explicar el misterio del encantamiento de las arañas. Sin embargo, el registro mítico es el que prevalece. La última palabra es la de los curanderos. En Hombres de maiz, encontramos la perspectiva narrativa característica de la "novela épica": la autoridad última no es la del conocimiento racional, sino la voz de la memoria colectiva, la encarnación de la ancestral comunidad carismática.

Otro texto clásico de la literatura latinoamericana que vale la pena examinar a la luz de la "novela épica" es Pedro Páramo (1954), de Juan 
Rulfo. Mediante el desafío de la verosimilitud realista, Rulfo estructura Pedro Páramo en tomo a un cronotopo que presenta la disolución de tiempo y espacio. Comala, un pueblo abandonado del bajío de Jalisco, se vuelve fundamental. Es el lugar sagrado donde una memoria, capaz de conjurar todos los tiempos posibles, supera al tiempo lineal. Si bien la estructura de la novela es fragmentaria y multiperspectivista, es posible reconstruir la lógica global de su heterogeneidad interna. En ella, encontramos nuevamente un narrador anónimo cuyo discurso permite una restauración de la historia del pueblo de Comala. Similar a Hombres de maíz, este trabajo no emplea la clásica autoridad narrativa del realismo, sino, por el contrario, una autoridad carismática. En este caso, la historia se vuelve comprensible cuando el héroe individual, Juan Preciado, se une a los muertos, todas las víctimas de los abusos del padre que el busca encontrar. Mediante una parodia de la búsqueda de Telémaco, aquí el individuo literalmente se disuelve en un abrazo de muerte. La búsqueda de Juan Preciado se vuelve así la recuperación de la voz de la memoria colectiva.

En todas las novelas que hernos examinado aquí, hay una evidente paradoja. La renovación carismática supondría la posibilidad de comunicación con un público lector amplio y heterogéneo. Aún dejando de lado obstáculos como analfabetismo, falta de cultura literaria, o escasos hábitos de lectura, la propia naturaleza formal de estos textos contradice sus ambiciones de popularidad incluyente. Esto por una razón simple: no son fáciles de leer. Hombres de Maiz es el caso extremo, no solamente exige una concentración intensa sino demanda que sus lectores estén aptos para descifrar sus intrincadas referencias a las culturas grecolatina y maya. En menor grado, El reino de este mundo y Pedro Páramo son también obras herméticas, en el sentido de la estética moderna de Adorno, llenas de referencias eruditas.

Este sólo hecho basta para destacar la novedad de Cien años de soledad, del colombiano Gabriel García Márquez (1928). Cien años de soledad es exitosa, no solamente por reactualizar la forma de la "novela épica", sino por adquirir, de hecho, el carisma que ninguno de sus predecesores logró. Es cierto que es una novela de virtuosismo narrativo cuidadosamente construido, que no sería posible sin la asimilación de la experiencia novelística moderna. Pero es también, y de manera sorprendente, lo que Roland Barthes llamaría un texto "legible", es decir una textualidad capaz de transparentarse y revelarnos una presencia del mundo. De esta forma 
esta novela logra la cualidad ingenua del mundo épico, que reclamaba Georg Lukács en su Teoría de la novela.

Cien años de soledad es tal vez el libro más comentado y el peor comprendido de la literatura latinoamericana, el monumental corpus crítico que la comenta viene a ser una suerte de testimonio de la esterilidad de la crítica académica. Sin embargo, la lógica de su cronotopo ha sido ampliamente explicada. Continúa la tradición de las novelas anteriores que restablecen la dinámica entre el centro y la periferia, disolviendo el tiempo lineal. Tal vez ha sido Franco Moretti el único crítico lo suficientemente perceptivo para notar algo fundamental y novedoso con respecto a sus antecedentes literarios inmediatos ${ }^{37}$. En Cien años de soledad, lo mágico no está en lo primitivo sino en lo moderno. Cuando el tiempo moderno toca finalmente Macondo, es sólo para mostrar los límites de la racionalización, puesto que Macondo es realmente una caricatura de la modernización.

El atractivo de la novela radica en lograr el ideal épico de la autoevidencia. Moretti muestra la virtual ausencia de ironía en la textura de Cien años. A pesar del intrincado progreso del argumento, la novela no aparece ante sus lectores como problemática. La clave es que García Márquez ha tenido éxito en configurar la lógica interna de la oralidad dentro de los confines del lenguaje literario. Porque para él la oralidad no es un problema de estilización literaria del dialecto oral al nivel de la elocución. De hecho, la novela está escrita en idioma letrado, casi limpio de localismos opacos, que abundan en otras novelas latinoamericanas. Los mecanismos de la oralidad funcionan aquí en los niveles de invención y disposición. En otras palabras, la calidad oral es creada principalmente mediante la densidad anecdótica y una autoridad narrativa sustentada en otros relatos que el texto entreteje. Este es precisamente el mecanismo del sentido común en una comunidad tradicional, donde existe un espesor de experiencias compartidas de carácter narrativo. El modo de comunicación literaria de este texto requiere indudablemente de empatía, y por tanto el mecanismo principal de autoridad literaria en Cien años se construye a partir de la empatía épica, revelando claramente el deseo de ir hacia la ingenuidad del mundo premoderno.

Muchas lecturas enfatizan el carácter autodestructivo de la novela y relacionan esto a la lógica cíclica y fatal del tiempo mítico: al repudiar el progreso anula cualquier redención posible. Esta lectura se apoya en el argumento mismo. Sabemos que la historia de Macondo fue profetizada 
y relatada en los manuscritos del gitano Melquíades. Pero una lectura más cuidadosa termina por revelar que el mecanismo de la narración es más sutil que este vínculo profético. Melquíades sabe, con seguridad, el desenlace de la saga de los Buendía, pero la escritura de la novela no corresponde, en un sentido estricto, a Melquíades. ¿Quién es entonces el narrador? El mecanismo narrativo es aquí similar al de Pedro Páramo, en el cual una voz anónima ubicada en otro plano relata la saga. Tal vez esta voz está localizada en un futuro utópico donde la historia entrega su carácter ejemplarizante, a la manera de la épica tradicional. De esta forma el final afirma explícitamente el significado de la historia: "Porque las estirpes condenadas a cien años de soledad no tenían una segunda oportunidad sobre la tierra". ${ }^{38}$ Es una intersubjetividad popular hablando a través de la memoria colectiva.

El éxito editorial de esta novela y su fórmula ha abierto el camino a una plétora de imitaciones en América Latina y orros países del "Tercer Mundo". Sin embargo, de la manera como la novela ha sido difundida y recibida la ha convertido indistinguible de los topos más tradicionales del exotismo. Tal vez haya que reconocer que el impulso crítico de la novela épica ha sido agotado, y esto no es solamente el agotamiento de un paradigma estético sino, en cierto sentido, también del propio programa del nacionalismo carismático. El realismo mágico o, como lo denominan algunos críticos actuales, el macondismo acaso ya no ilumina las complejas dinámicas de la temporalidad en las sociedades latinoamericanas, sino que se ha vuelto una construcción imaginaria auto-evidente que entrega entretenimiento y el aura de autenticidad de mundos primitivos a lectores nostálgicos.

\section{Una estética de la Modemidad periférica}

Para concluir, recapitulemos algunas de las interconecciones entre lo político y lo estético en la "novela épica". Roberto González Echavarría ha mostrado correctamente que la diferencia más importante entre el surrealismo y la estética de lo "real maravilloso" es que la última se presenta a sí misma como la ontología de América Latina. Lo "real maravilloso" no está confinado al espacio de representación sino es una cualidad real del referente. Por tanto, es comprensible que lo maravilloso como una fuerza efectiva requiera una nueva forma de realismo. Con toda seguridad, esta ontologización de lo maravilloso tiene claramente implicaciones irracionalistas, como consecuencias lógicas del vínculo entre racionalismo carismático y pensamiento antimoderno europeo. El elemento más evi- 
dente de este vínculo es la noción de la incomunicabilidad de culturas y civilizaciones como lo presente la filosofía de la historia de Spengler. Una posible lectura de esta creencia pondría a América Latina y Europa como esencialmente diferentes, una posición que tiene sus beneficios como también sus riesgos para comprender la compleja lógica espacio-temporal de la modernidad. Por un lado, pues, esta nueva forma simbólica ofrece una condición de posibilidad para la heterogeneidad de la región y prepara el camino rumbo al reconocimiento de grupos sociales, excluidos del proyecto modernizador. Por otro lado, sin embargo, esta posición puede dejarnos desarmados para criticar las irracionalidades que han atormentado a las sociedades latinoamericanas, tales como autoritarismo, las desigualdades y la violencia.

Lo "real maravilloso" se diluye en el irracionalimo cuando no somos capaces de trascender la limitada racionalidad de la modernización. Por lo tanto, es posible desarrollar conclusiones más positivas, las cuales pueden hacer justicia al impulso crítico del diálogo latinoamericano con el Surrealismo y la Vanguardia. Anteriormente, hice notar que la modernización en América Latina fracasa en eliminar ciertos aspectos de sus sociedades premodernas y por lo tanto no los integra en el tiempo del capital; su heterogeneidad cultural se manifiesta aun en la persistencia de tiempos inhóspitos. ${ }^{39} \mathrm{Sin}$ embargo, la perspectiva eurocéntrica que ha dominado la auto-conciencia latinoamericana ha tendido a desechar este impasse como una instancia de barbarie o irracionalidad. Aníbal Quijano nos permite considerar lo "real maravilloso" y la "novela épica" desde una óptica diferente. Para él, no es ni nostalgia ni exotismo, sino la expresión de una experiencia de tiempo diferente:

"El pasado atraviesa el presente, de un modo diferente a como estaba instalado en el imaginario europeo anterior a la modernidad. Es decir, no como nostalgia de una edad dorada, por ser o haber sido el continente de la inocencia. Entre nosotros el pasado es o puede ser una vivencia del presente, no su nostalgia. No es la inocencia perdida, sino la sabiduría integrada, la unidad del árbol del conocimiento en el árbol de la vida, lo que el pasado defiende en nosotros, contra el racionalismo instrumental, como sede de una propuesta alternativa de racionalidad. La realidad es vista, se hace ver, de ese modo como totalidad, con toda su magia La racionalidad, aquí, no es un desencantamiento del mundo, sino la inteligibilidad de su totalidad. Lo real no es racional, sino en tanto no excluya su magia" 40 
A partir de esta racionalidad ampliada emerge una intersubjetividad que es impensable en la lógica del tiempo dominante de la modernidad. Esta intersubjetividad es lo que la forma de la "novela épica" anticipa. De nuevo, nosotros podríamos sospechar de este optimismo como un caso de nostalgia regresiva. Sin embargo, Quijano halla un referente social concreto de esta intersubjetividad:

"En el seno mismo de las ciudades latinoamericanas, las masas de dominados están constituyendo nuevas prácticas sociales fundadas en la reciprocidad, en su implicada equidad, en la solidaridad colectiva y, al mismo tiempo, en la libertad de opción individual y en la democracia de las decisiones colectivamente consentidas, contra toda imposición externa" "1.

¿Un simple deseo? Tal vez. Sin embargo, la recuperación de lo primitivo que propone la "novela épica" nos permite considerar las divergentes experiencias de tiempo como algo distinto a lo irracional. Muy por el contrario: existe una racionalidad viviente en las subjetividades populares detrás de algunos nuevos movimientos que hunden sus raíces en lo social, tales como las comunidades cristianas inspiradas en la Teología de la Liberación. En los márgenes de la modernidad, encontramos remanentes efectivos de una racionalidad comunicativa con un potencial futuro. La "novela épica" torna su realidad visible y comprensible, y esto constituye su contribución a la cultura contemporánea y a la larga marcha de América Latina de apropiarse de su destino.

NotAs

1 Este artículo se publicó originalmente en inglés en el $\mathrm{N}^{\circ} 49$ de Cultural Critique, correspondiente al otoño de 2001. Oswaldo Camino hizo una primera versión de mi artículo al castellano, la cual sufrí las inevitables enmiendas que reclama el paso del tiempo y el cambio de matriz lingüística

2 La expresión de hecho pertenece a Carpentier, quien, en una entrevista concedida a Elena Poniatowska usa esta expresión, para describir la clase de novelística en la cual él se halla envuelto.

3 Georg Lukács, Teoria de la novela, Barcelona: Edhasa, 1971.

- Cândido, António, "Literatura y subdesarrollo", en América Latina en su literatura, ed. César Fernández Moreno. México: Siglo XXI y UNESCO, 1972, pp. 335-353..

5 Véase Francisco Zapata, Ideología y política en América Latina. México: Colegio de México, 1990. 
- Yo he tomado la noción de comunidad carismática del sobresaliente estudio de Russell A. Berman, The rise of the German novel (Cambridge: Harvard University Press, 1989). Él elabora esta noción a partir de la discusión del concepto de carisma de Max Weber

, Ibid., 50.

B Ibid., 51

- Octavio Paz ilustra cómo el movimiento popular que anima la Revolución Mexicana, especialmente la dirigida por Emiliano Zapata en el Sur, está impregnada por un modelo similar al de la comunidad carismática. Sin embargo, uno no debe olvidar que el significado de estos movimientos permanecen obscuros a las élites intelectuales. Es solamente después de revisar los recuentos históricos, que su carácter se ha vuelto más visible. Véase Claude Fell, "Vuelta a El laberinto de la soledad (conversación con Octavio Paz)," en Octavio Paz, pasión crítica, ed. Hugo Verani (Barcelona: Seix Barral,1990); su discusión de la rebelión zapatista está en las páginas 113-17.

10 Octavio Paz corrobora el impacto de la Revista de Occidente en las élites de la cultura latinoamericana: "leíamos mucho las publicaciones de la Revista de Occidente que dirigia Ortega y Gasset y así mi generación comenzó a familiarizarse con la filosofla alemana moderna, la fenomenologia de Husserl y sus sucesores y discípulos" (Rita Guibert, "Octavio Paz", entrevista, ibid., 80).

1 Para una estimación del clima cultural de esos autores latinoamericanos que mantuvieron un diálogo con la Vanguardia estética, véase Roberto González Echevarría, Alejo Carpentier, The pilgrim at bome, (Austin: University of Texas Press, 1990), especialmente el segundo capitulo, "Lord, praised be thou!" 34-95.

12 La traducción de este trabajo, encomendada al filósofo Manuel García Morente, apareció en 1923 en la serie Biblioteca de las Ideas del siglo XX, de la casa editorial de Revista de Occidente. Tuvo una introducción del mismo José Ortega y Gasset.

13 A gunos podrían objetar esto, citando la aventura de algunos de los surrealistas dentro del Partido Comunista francés. Sin embargo, esto fue más el resultado del activismo de artistas individuales que un intento organizado de relacionar la estética con la política. Al final, esta experiencia resultó ser desastrosa. El surrealismo permaneció como un movimiento cultural contestatario que no pudo ser traducido en fórmulas politicas viables. Véase Helena Lewis, The politics of Surrealism (Nueva York: Paragon House 1988), y Martín Jay, Maraism and Totality (Berkeley y Los Angeles: University of California Press, 1984), especialmente el capitulo “Henri Lefebvre, the Surrealists, and the reception of Hegelian Marxism in France", 276-99.

14 Entre los escritores latinoamericanos más prominentes que tuvieron relación directa con los movimientos de vanguardia en Europa encontramos a Arturo Uslar Pietri, de Venezuela; César Vallejo, de Perú; Luis Cardoza y Aragón, de Guatemala; Pablo Neruda, de Chile; y Octavio Paz, de México.

15 De Asturias, véase Jean Cassou, "Asturias en París: Un descubrimiento recíproco;" Georges Pillement, "El París que Asturias ha visto y vivido"; Paulette Patout, "La cultura latinoamericana en París entre 1910 y 1936"; Y Marc Cheymol, "Miguel 
Ángel Asturias entre latinidad e indigenismo: Los viajes de Prensa Latina y los seminarios de cultura maya en la Sorbona," todos en Miguel Ángel Asturias, París, 1924-1933: Periodismo y creación literaria, ed. Amos Segala (Madrid: Colección Archivos, 1988). De Carpentier, véase Roberto González Echevarría, Alejo Cappentier, The Pilgrim at Home (Austin: University of Texas Press, 1990).

16 Asturias escribió para El Imparcial; Carpentier para Carteles y El Social.

17 José Luis López Álvarez, Conversaciones con Miguel Angel Asturias (Madrid: Magisterio Español, 1974), p. 80.

16 Ibid., 81.

19 El Nacional de Caracas, 16 de Septiembre de 1945, citado en Alejo Carpentier, Entrevistas, ed. Virgilio López Lemus (Habana: Editorial Letras Cubanas, 1985), 19-21.

$20 \quad$ Ibid., 19.

21 Entrevista con Radio Televisión Francesa, citada en Entrevistas, 92.

22 "Visión de América. El último buscador de El Dorado," en Alejo Carpentier, Crónicas 1: Arte, Literatura, Polatica, vol. 8 de sus obras completas. (México: Siglo XXI Editores, 1985).

23 Ibíd., 199-200.

24 Yo me baso en la concepción de Paul Ricoeur de triple mimesis, como es expuesta en el primer volumen de Tiempo y narrativa. Él considera la mimesis, no simplemente como una copia inerte de la realidad sino como un proceso activo de prefiguración, configuración, y transfiguración. Yo creo que este enfoque ayuda a superar los términos de la vieja disputa entre realismo y modernismo en la crítica literaria marxista. Véase Paul Ricoeur, Tiempo y narrativa, vol. 1 (México: Siglo XXI, ).

2s Véase Dario Villanueva, Theories of Literary Realism (Albany: SUNY Pres, 1997); y Lilian R. Furst, All is True: The Claims and Strategies of Realist Fiction (Durham, N.C.: Duke University Press, 1995).

26 Berman, Op. Cit., 74-75.

27 Véase Carril Emerson y Gary Saul Morson, Mikhail Bakbtin: Creation of a Prosaics (Stanford, Calif.: Stanford University Press, 1990).

20 Schwarz, Roberto, Misplaced Ideas: essays on Brazilian Culture, (Londres y Nueva York: Verso, 1992).

29 A lo inadecuado de los medios de representación literaria debe agregarse el carácter militante de muchas de las novelas. Su forma alegórica puede también explicarse ya que en muchos casos ellos no son únicamente objetos de contemplación estéticos sino, además, manifiestos políticos.

so Podemos encontrar una manifestación brillante de un cronotopo latinoamericano en la película incompleta de Sergei Eisenstein iQue viva México! Aparentemente, él discutió algunas ideas acerca de la experiencia de tiempo y espacio de México, con algunos artistas e intelectuales de este país. Uno podría argumentar que este 
cronotopo está ya presente en el muralismo mexicano, particularmente en el trabajo de Diego Rivera. Este tema excede los límites de este ensayo. Véase Inga Karetnikova, México according to Eisenstein (Albuquerque: University of México Press, 1991) y Ricardo Roque Baldovinos, ${ }^{a}$ Un fresco cinematográfico, una sinfonfa mexicana: Eisenstein y México", revista Cultura Nos. 87-88, mayo-diciembre de 2002.

31 Véase José Vasconcelos y sus ideas acerca sobre la "raza cósmica" en su ensayo La raza cósmica: Misión dela raza iberoamericana (Madrid: Aguilar, 1966).

32 Para una exposición de la ideología del pan-latinismo y su impacto en América Latina, véase John L. Phelan, "Pan-latinismo, la Intervención francesa en México (1861-1867), y la Génesis de la Idea de América Latina," en Juan A. Ortega y Medina, ed., Conciencia y autenticidad bistóricas: Escritos en bomenaje a Edmundo O'Gorman (México: UNAM, 1968).

3) Véase James Clifford, The Predicament of Culture: Twentieth century ethnography, literature and art, especialmente el capítulo "On Ethnographic Surrealism" (Cambridge: Harvard University Press, 1988).

34 Asibal Quijano, "Modernidad, Identidad y Utopía en América Latina," en Edgardo Lander (ed.) Modemidad y Universalismo, (Caracas: Rectorado de la Universidad Central de Venezuela y UNESCO, 1991), Pp. 27-42. El pasaje citado se encuentra en la página 37.

3s Véase González Echevarriá, Op. Cit

36 Véase Asturias, París 1924-1932.

3) Franco Moreti, World Epic: The World System from Goethe to Garcia Mdrquez, (Londres: Verso, 1996).

38 Gabriel García Márquez, Cien años de soledad (Madrid: Cátedra, 1999), p. 559.

39 Este rasgo de las sociedades periféricas ha sido explicado por el filósofo alemán Ernst Bloch con su concepto de asincronismo. Véase Ernst Bloch, "Nonsynchronism and Dialecs", New Geman Critique 11 (Primavera 1977).

to Quijano, op. cit., Pp. 37-38.

$4 \quad$ Ibíd., p. 41 